\title{
Gastro-oesophageal reflux disease in type 2 diabetics: symptom load and pathophysiologic aspects - a retro-pro study
}

Regina Promberger ${ }^{1}$, Johannes Lenglinger ${ }^{1}$, Otto Riedl ${ }^{2,3}$, Gernot Seebacher ${ }^{2}$, Wolf Hans Eilenberg ${ }^{1}$, Johannes Ott ${ }^{4}$, Franz Martin Riegler ${ }^{1}$, Michael Gadenstätter ${ }^{2^{\wedge}}$ and Christoph Neumayer ${ }^{5^{*}}$

\begin{abstract}
Background: Information about gastro-oesophageal reflux disease (GERD) in patients with Diabetes mellitus type 2 (T2D) is scarce, although the incidence of both disorders is increasing.

We aimed to determine GERD symptoms and their underlying pathophysiologic characteristics in T2D patients.

Methods: This "retro-pro" study compared 65 T2D patients to a control group of 130 age- and sex-matched non-diabetics. GERD was confirmed by gastroscopy, manometry, pH-metry and barium swallow.

Results: In patients with T2D compared to controls, dysphagia (32.3\% vs. 13.1\%; $p=0.001$ ) and globus sensation $(27.7 \%$ vs. $13.8 \% ; p=0.021)$ were found more frequently, whereas heartburn $(76.9 \%$ vs. $88.5 \% ; p=0.046)$ and regurgitation ( $47.7 \%$ vs. $72.3 \% ; p=0.001)$ were predominant in non-diabetics. Despite higher body mass indices ( $31.1 \pm 5.2$ vs. $\left.27.7 \pm 3.7 \mathrm{~kg} / \mathrm{m}^{2} ; \mathrm{p}<0.001\right)$, hiatal hernia was less frequent in T2D patients compared to controls (60.0\% vs. 90.8\%, $\mathrm{p}<0.001)$. Lower oesophageal sphincter (LES) pressure was higher in patients with T2D (median 10.0 vs. $7.2 \mathrm{mmHg}, p=0.016$ ). DeMeester scores did not differ between the groups. Helicobacter pylori infections were more common in T2D patients ( $26.2 \%$ vs. $7.7 \%, p=0.001)$. Barrett metaplasia ( $21.5 \%$ vs. $17.7 \%$ ), as well as low- (10.8\% vs. 3.8\%) and high-grade dysplasia (1.5\% vs. 0\%) were predominant in T2D patients.

Conclusions: T2D patients exhibit different GERD symptoms, higher LES pressures and a decreased prevalence of hiatal hernia than non-diabetics, which may be related to worse oesophageal motility and, thus, a more functional rather than anatomical cause of GERD. Low-grade dysplasia was more than twice as high in T2D than in non-diabetics patients.
\end{abstract}

Trial registration: Ethics committee of the Medical University of Vienna, IRB number 720/2011.

Keywords: Diabetes, GERD, Dysphagia, Heartburn, Hiatal hernia

\section{Background}

Gastro-oesophageal reflux disease (GERD) is one of the most common disorders of the upper gastrointestinal tract in developed countries. Up to $40 \%$ of the adult population suffers from reflux symptoms [1]. At the same time, diabetes mellitus (DM), especially DM type 2 (T2D), which accounts for up to $95 \%$ of diabetes cases, is dramatically

\footnotetext{
* Correspondence: christoph.neumayer@meduniwien.ac.at

Deceased

${ }^{5}$ Division of Vascular Surgery, Department of Surgery, Medical University of Vienna, Vienna, Austria

Full list of author information is available at the end of the article
}

increasing worldwide. In 2010, 284.8 million people were affected. It has been estimated that that number will rise to 438.7 million diabetic adults in the year 2030 [2]. Thus, both disorders are of increasing medical and socioeconomic interest.

T2D has been described as a possible risk factor for the development of GERD [3-6]. More recently, it has been suggested that the metabolic syndrome defined by visceral fat accumulation, dyslipidaemia, hypertension, and hyperglycaemia correlates with the occurrence of GERD [7]. As recently reviewed, several pathophysiologic factors may explain this finding: (i) hyperglycaemia causes increased gastric $\mathrm{H}^{+}$secretion, higher levels of bile acids, and 
reduced bicarbonate levels; (ii) delayed oesophageal and gastric emptying, increased rates of transient lower oesophageal sphincter (LES) relaxations, and decreased LES pressure has been reported during hyperglycaemia in patients with T2D; and, (iii) hiatal hernia and increased obesity rates may also contribute to the development of GERD in these patients [8].

However, many of the reviewed studies did not discriminate between GERD-specific symptoms and general upper gastrointestinal symptoms, which are frequently found in diabetics [8]. Moreover, most studies were based on GERD questionnaires and did not determine GERD using standard pH-metry and manometry $[3-5,9,10]$. To date, no study exists about GERD and GERD-specific symptoms in patients with T2D that has included upper gastrointestinal endoscopy, barium oesophagogram, manometry, and 24hour oesophageal $\mathrm{pH}$-monitoring concurrently.

The aim of this study was to investigate GERD-specific symptoms and reflux parameters in patients with T2D using these standard diagnostic tools. Second, the results were compared to non-diabetic GERD-patients in order to explore possible diabetes-related differences. Special emphasis was placed on extra-oesophageal GERD symptoms that have not been described for diabetics thus far.

\section{Methods}

\section{Patient selection and assessment of symptom load}

All patients referred to the motility laboratories of our institutions for symptoms suggestive of GERD between January 2007 and January 2009 were considered eligible for this "retro-pro" case control study [11]. Exclusion criteria were a body mass index (BMI) $>35 \mathrm{~kg} / \mathrm{m}^{2}$, type 1 (juvenile) diabetes, oesophageal motility disorders other than ineffective oesophageal motility, and a history of oesophageal or gastric surgery. The study group consisted of patients with T2D and GERD-related symptoms. The diagnosis of T2D was based on the criteria established by the American Diabetes Association [12]. Of a total of 588 patients, a control group of 130 nondiabetic GERD patients (22.1\%) was selected using age and sex as matching criteria. A detailed history was taken from all patients and they were asked to answer a standardized questionnaire about upper gastrointestinal symptoms before oesophageal function tests. Patients were questioned regarding the presence of upper gastrointestinal symptoms, namely heartburn, epigastric pain, regurgitation, respiratory symptoms, odynophagia, globus sensation, dysphagia, flatulence, chronic cough, hoarseness, bronchitis, and bronchial asthma. Bronchitis and bronchial asthma were only accepted as comorbidities if a specialist in respiratory medicine had diagnosed them. All patients' medication was also assessed, with a focus on proton-pump inhibitors, prokinetics, and anti-depressants.
Data were prospectively gathered by a research assistant and entered in a database. The study was approved by the ethics committee of the Medical University of Vienna (IRB number: 720/2011). The study was carried out in accordance with the "Good Scientific Practice" Standards of the Medical University of Vienna, which are based on the ethical standards of the Helsinki Declaration of 1975. Written informed consent was obtained from all study participants.

\section{Oesophageal testing}

All patients underwent upper gastrointestinal endoscopy, stationary oesophageal manometry, barium oesophagogram, and 24-hour oesophageal $\mathrm{pH}$-monitoring. Thereby, GERD was confirmed for all patients of both the T2D and the control group. Upper gastrointestinal endoscopy was routinely performed with sedation on a Fujinon Video Endoscope System (Fujifilm Holdings Corporation, Tokyo, Japan). Esophagitis was graded using the Savary and Miller classification system [13]. A hiatal hernia was diagnosed when the difference between the position of the crural impression and the commencement of gastric-type folds was $2 \mathrm{~cm}$ or more. The size of the hiatal hernia was noted. Standardized biopsies were obtained from the oesophagus, the squamocolumnar junction, and the gastric antrum. Visible tongues or circular segments of columnar epithelium were biopsied. A diagnosis of intestinal metaplasia (Barrett's oesophagus) was made if the presence of well-defined goblet cells within columnar epithelium was confirmed by a pathologist who specialized in gastrointestinal disorders [14]. Laryngeal lesions, including inflammation, edema, leukoplakia, and ulcerations were also diagnosed or ruled out, either in the course of upper gastrointestinal endoscopy and/or laryngoscopy. An oto-laryngologist saw these patients and confirmed the lesions.

All patients underwent standard, stationary, pullthrough oesophageal manometry using the Sandhill EFT Impedance Manometry System ${ }^{\circ}$ (Sandhill Scientific, Colorado, USA) with Bioview Software ${ }^{\bullet}$ (Sandhill Scientific, Colorado, USA). LES resting pressure and swallow-induced relaxation was measured immediately distal to the respiratory inversion point. LES was considered mechanically defective if the mean end-expiratory pressure was below $8 \mathrm{~mm} \mathrm{Hg}$ and/or a total LES length < $2 \mathrm{~cm}$ or an abdominal length $<1 \mathrm{~cm}$ was encountered $[15,16]$. Oesophageal body motility was investigated with ten water swallows of $5 \mathrm{ml}$ at 30-second intervals. Propagation and amplitudes of swallow-induced contractions were recorded in the proximal, middle, and distal third of the oesophageal body. A contraction wave was considered to be ineffective if one or more of the following criteria applied: 1) amplitude in the distal oesophagus below $30 \mathrm{mmHg}$; 2) simultaneous propagation (> $20 \mathrm{~mm} / \mathrm{sec}$ ); or 
3) interrupted or dropped contraction waves (contraction amplitudes $<15 \mathrm{mmHg}$ ). Impaired oesophageal motility was diagnosed if more than $20 \%$ of oesophageal contraction waves fulfilled these criteria [17].

Twenty-four-hour oesophageal pH-monitoring was performed using the Sandhill GER Impedance $\mathrm{pH}$ Metry ${ }^{\circ}$ device (Sandhill Scientific, Colorado, USA) as described previously [18]. In short, a single-use catheter fitted with an antimony electrode was passed transnasally and positioned $5 \mathrm{~cm}$ proximal to the upper border of the LES. A calibration of buffer solutions of $\mathrm{pH} 1$ and $\mathrm{pH} 7$ was performed prior to each study. Endoluminal $\mathrm{pH}$ was recorded for 20-24 hours at a frequency of $0.25 \mathrm{~Hz}$, and data were stored in a portable data logger. Patients were instructed to follow their routine activities and to consume their usual diet. The patients recorded meal periods and times spent in recumbent positions. Sampled data were transferred to a computer for analysis using DeMeester's composite score as the main variable. A score of more than 14.7 indicated increased acid reflux. All medications that could possibly interfere with oesophageal motor function (i.e., metoclopramide, cisapride, nitrates, betaagonists, and calcium-channel blocking agents) or gastric acid secretion were discontinued at least seven days before the studies. The use of sucralfate was permitted until one day before reflux monitoring.

In addition, barium swallows, i.e., double-contrast oesophagographies, were performed in all patients through biphasic examination with upright air-contrast and prone single-contrast views of the oesophagus. The occurrence of spontaneous gastro-oesophageal reflux was assessed, and the presence and size of hiatal hernias were recorded.

\section{Statistical analysis}

Values are expressed as mean \pm standard deviation (SD), or median and interquartile range [IQR], if appropriate. Concerning general patient characteristics, the chi-square test and, if appropriate, Fisher's exact test, were used to compare proportions between groups. To compare differences, $\mathrm{t}$-tests and $\mathrm{u}$-tests were used. To compare proportions and differences in outcome parameters between the groups, univariate logistic regression models were used. For these, p-values of the likelihood ratio tests, odds ratios (OR) and $95 \%$ confidence intervals $(95 \% \mathrm{CI})$ are provided. Correlations were tested using Spearman rank correlations. $\mathrm{P}$ values $<0.05$ were considered statistically significant. The software SPSS 17.0 (SPSS Inc, Chicago, 1993-2007) was used for all statistical analyses.

\section{Results}

\section{Patient characteristics}

One-hundred-thirty non-diabetic GERD-patients were enrolled in the study as a control-group. General patient characteristics are summarized in Table 1. BMI levels were significantly higher in diabetic patients. When focusing on laboratory parameters, total cholesterol levels were higher in the control group, whereas HbA1c and triglyceride levels were higher in patients with T2D.

No differences were found between diabetics and nondiabetics concerning the use of proton pump inhibitors and pro-kinetics $(59 / 65$ [90.8\%] vs. $118 / 130$ [90.8\%], p > 0.05 ; and $4 / 65$ [6.2\%] vs. 10/130 [7.7\%], p > 0.05, respectively). Anti-depressants were used more frequently in diabetics than in non-diabetics $(14 / 65$ [21.5\%] vs. $7 / 130$ [5.4\%], $\mathrm{p}=0.001$, respectively).

When focusing on the characteristics of patients with T2D only, 56 subjects had T2D for a median duration of 5.0 years (IQR 3.0-10.0 years; 29 women, 36 men). Neither the duration of T2D, nor the duration of GERD correlated with HbA1c levels $(r=0.254, p=0.061$ and $r=-0.063, p=$ 0.617; respectively).

All diabetic subjects were treated dietetically. In addition, 49 patients $(75.4 \%)$ used hypoglycaemic agents, such as metformin $(40 / 65,61.5 \%)$, gliclacid $(6 / 65,9.2 \%)$, glibenclamid $(2 / 65,3.1 \%)$, and acarbose $(1 / 65,1.5 \%)$. Twelve patients (18.5\%) were insulin-dependent. The co-morbidities of T2D patients comprised arterial hypertension in 58.5\% (38/65), peripheral neuropathy in 32.3\% (21/65), diabetic retinopathy in $13.8 \%$ (9/65), peripheral arterial disease in $12.3 \%(8 / 65)$, and diabetic nephropathy in $6.2 \%(4 / 65)$.

\section{GERD-related symptoms}

Table 2 provides data about GERD-related symptoms. In short, patients with T2D reported dysphagia and globus sensation more frequently, whereas heartburn, regurgitation, and flatulence were predominant in non-diabetics. The prevalence of respiratory symptoms did not differ between both groups. When comparing the sum of GERD symptoms between patients with and without T2D, there was no essential difference (median 3, IQR $2-5$ vs. median 4 , IQR $3-5$, respectively; $\mathrm{p}=0.210$ ). Likewise, diabetic patients with neuropathia and those without did not differ concerning the sum of GERD symptoms (median 3, IQR 2-4, vs. median 3, IQR 2-5, respectively; $\mathrm{p}=0.411$ ). The duration of diabetes had no impact on GERD symptoms either.

\section{Laryngeal findings and oesophageal testing}

Laryngeal lesions, including inflammation, oedema, leukoplakia, and ulcerations were observed more frequently in patients with T2D $(16.9 \%$ vs. $7.0 \%$ in nondiabetics, $\mathrm{p}=0.032$ ).

Results of oesophageal testing are given in Table 3. When focusing on findings with differences between diabetic and non-diabetic patients only, upper GI endoscopy revealed a hiatal hernia in $60.0 \%$ of patients with 
Table 1 Comparison of general patient characteristics and laboratory parameters between GERD patients with and without T2D

\begin{tabular}{|c|c|c|c|}
\hline & T2D GERD patients & Non-diabetic GERD patients & $\mathrm{p}$ \\
\hline Patients ( $\mathrm{n}$ ) & 65 & 130 & - \\
\hline Females (n [\%]) & 29 [44.6\%] & $58[44.6 \%]$ & n.s. ${ }^{*}$ \\
\hline Age (years, mean $\pm \mathrm{SD}$ ) & $58.6 \pm 9.2$ & $58.5 \pm 8.8$ & n.s. ${ }^{* *}$ \\
\hline $\mathrm{BMI}\left(\mathrm{kg} / \mathrm{m}^{2}\right.$, mean $\left.\pm \mathrm{SD}\right)$ & $31.1 \pm 5.2$ & $27.7 \pm 3.7$ & $<0.001^{* *}$ \\
\hline Smoking (n [\%]) & 18 [27.7\%] & 12 [10.1\%] & $0.002^{*}$ \\
\hline Duration of GERD symptoms (years, median [IQR]) & $5.0[3.0 ; 10.0]$ & $5.0[2.0 ; 11.0]$ & n.s. ${ }^{* * *}$ \\
\hline $\mathrm{HbA1c}(\%)$ & $7.2 \pm 1.1$ & $5.3 \pm 0.9$ & $<0.001^{* *}$ \\
\hline Total cholesterol (mg/d, mean \pm SD) & $204.2 \pm 44.9$ & $217.3 \pm 38.0$ & $0.013^{* * *}$ \\
\hline $\mathrm{LDL}^{*}(\mathrm{mg} / \mathrm{dl}$, mean $\pm \mathrm{SD})$ & $126.6 \pm 32.6$ & $134.8 \pm 36.9$ & n.s..$^{* * *}$ \\
\hline $\mathrm{HDL}^{\#}(\mathrm{mg} / \mathrm{dl}$, mean $\pm \mathrm{SD})$ & $56.3 \pm 16.0$ & $60.2 \pm 18.3$ & n.s..$^{* * *}$ \\
\hline Triglycerides (mg/dl, mean \pm SD) & $183.0 \pm 118.9$ & $128.8 \pm 66.4$ & $<0.001^{* * *}$ \\
\hline Blood urea nitrogen (mg/dl, mean $\pm \mathrm{SD})$ & $15.1 \pm 4.9$ & $13.7 \pm 4.5$ & n.s.*** \\
\hline Creatinine $(\mathrm{mg} / \mathrm{dl}$, mean $\pm \mathrm{SD})$ & $1.0 \pm 0.2$ & $0.9 \pm 0.1$ & n.s..$^{* * *}$ \\
\hline
\end{tabular}

$n$ number, $S D$ Standard deviation, IQR Interquartile range, BMI Body mass index, $n$.s. Not significant; ${ }^{*}$ chi-square test, ${ }^{* *} \mathrm{t}$-test, ${ }^{* * *} \mathrm{u}$-test, $\mathrm{p} \mathrm{p}$-value.

T2D compared to $90.8 \%$ of non-diabetics $(\mathrm{p}<0.001)$. The sizes of hiatal hernias did not differ significantly between the groups (median $4 \mathrm{~cm}$ [IQR 3-5] for patients with T2D vs. median $5 \mathrm{~cm}$ [IQR 4-7] for non-diabetics, $\mathrm{p}=0.060$ ). An analysis of barium esophagograms revealed hiatal hernias more frequently in non-diabetics. Helicobacter pylori infections were more common in patients with T2D. Manometry revealed a significantly higher median pressure of LES for diabetics.

HbA1c levels in patients with T2D did not correlate with LES pressure, relaxation time, or peristalsis $(r<0.30$, $\mathrm{p}>0.05$ for all three Spearman rank correlations).
Diabetes treatment-specific analyses

Symptoms, endoscopic, $\mathrm{pH}$, and manometric parameters in patients with T2D were also analyzed according to the diabetes-specific therapy the patients were receiving. There were no differences in all parameters between those patients with dietary restrictions only $(\mathrm{n}=10)$, those with dietary restrictions and oral hypoglycaemic agents $(\mathrm{n}=43)$, and those who were also insulin-dependent $(\mathrm{n}=$ 12), apart from epigastric pain. This symptom was reported less frequently in patients on oral medication (51.2\%) than in patients with dietary restrictions only $(80 \%)$ and those with additional insulin therapy $(83.3 \%, \mathrm{p}=0.045)$.

Table 2 Upper gastrointestinal symptoms in diabetic and non-diabetic GERD patients

\begin{tabular}{|c|c|c|c|c|}
\hline & $\begin{array}{l}\text { T2D GERD } \\
\text { patients }\end{array}$ & $\begin{array}{l}\text { Non-diabetic } \\
\text { GERD patients }\end{array}$ & $\begin{array}{c}\text { OR } \\
(95 \% \mathrm{Cl})\end{array}$ & $p$ \\
\hline & $n=65$ & $n=130$ & & \\
\hline Heartburn & $50(76.9)$ & $115(88.5)$ & $0.47(0.21 ; 0.99)$ & 0.046 \\
\hline Epigastric pain & $40(61.5)$ & $85(65.4)$ & $0.85(0.46 ; 1.57)$ & n.s. \\
\hline Regurgitation & $31(47.7)$ & $94(72.3)$ & $0.36(0.20 ; 0.67)$ & 0.001 \\
\hline Respiratory symptoms & $40(61.5)$ & $82(63.1)$ & $0.94(0.51 ; 1.73)$ & n.s. \\
\hline Odynophagia & $6(9.2)$ & $9(6.9)$ & $1.37(0.47 ; 4.02)$ & n.s. \\
\hline Globus sensation & $18(27.7)$ & $18(13.8)$ & $2.38(1.14 ; 4.80)$ & 0.021 \\
\hline Dysphagia & $21(32.3)$ & $17(13.1)$ & $3.40(0.90 ; 12.79)$ & 0.001 \\
\hline Flatulence & $13(20.0)$ & $59(45.4)$ & $0.30(0.15 ; 0.61)$ & 0.001 \\
\hline Chronic cough & $28(43.1)$ & $59(45.4)$ & $0.91(0.50 ; 1.66)$ & n.s. \\
\hline Hoarseness & $17(26.2)$ & $32(24.6)$ & $1.08(0.55 ; 20.14)$ & n.s. \\
\hline Bronchitis & $10(15.4)$ & $22(16.9)$ & $0.89(0.39 ; 2.02)$ & n.s. \\
\hline Asthma bronchiale & $9(13.8)$ & $28(21.5)$ & $0.59(0.26 ; 1.33)$ & n.s. \\
\hline
\end{tabular}

n.s. not significant, $\mathrm{p}$ p-value.

Data are provided as $\mathrm{n}(\%)$, multiple citations possible; all parameters were tested using univariate logistic regression models. 
Table 3 Results of oesophageal testing

\begin{tabular}{|c|c|c|c|c|}
\hline & $\begin{array}{l}\text { T2D GERD patients } \\
n=65\end{array}$ & $\begin{array}{l}\text { Non-diabetic GERD patients } \\
\qquad n=130\end{array}$ & OR $(95 \% \mathrm{Cl})$ & $\mathrm{p}$ \\
\hline \multicolumn{5}{|l|}{ Upper Gl endoscopy } \\
\hline Hiatal hernia (n [\%]) & $39[60.0]$ & $118[90.8]$ & $0.49(0.23 ; 0.98)$ & $<0.001$ \\
\hline Oesophagitis (n [\%]) & 30 [46.2] & $43[33.1]$ & $1.86(1.01 ; 3.43)$ & n.s. \\
\hline Barrett metaplasia (n [\%]) & $11[16.9]$ & 35 [26.9] & $0.58(0.27 ; 123)$ & n.s. \\
\hline \multicolumn{5}{|l|}{ Histology } \\
\hline Esophagitis (n [\%]) & 38 [58.5] & $73[56.2]$ & $1.32(0.73 ; 2.42)$ & n.s. \\
\hline Barrett metaplasia (n [\%]) & $14[21.5]$ & $23[17.7]$ & $1.42(0.67 ; 3.02)$ & n.s. \\
\hline Low-grade dysplasia (n [\%]) & $7[10.8]$ & $5[3.8]$ & $3.80(1.07 ; 13.51)$ & n.s. \\
\hline High-grade dysplasia (n [\%]) & $1[1.5]$ & $0[0]$ & $3.28^{*} e^{9}(0 ;$ inf $)$ & n.s. \\
\hline Helicobacter pylori (n [\%]) & $17[26.2]$ & $10[7.7]$ & $4.72(1.97 ; 11.32)$ & 0.001 \\
\hline \multicolumn{5}{|l|}{ Manometry } \\
\hline LES pressure (mm Hg, median [IQR]) & $10.0[6.1 ; 15.0]^{\#}$ & $7.2[3.7 ; 11.7]$ & $1.06(1.01 ; 1.12)$ & 0.016 \\
\hline Absent or decreased peristalsis ( $[\%]$ ) & $16[27.6]^{\#}$ & $23[17.8]^{+}$ & $1.76(0.85 ; 3.65)$ & n.s. \\
\hline \multicolumn{5}{|c|}{ Twenty-four-hour oesophageal pH-monitoring } \\
\hline DeMeester score (median [IQR]) & $24.6[12.1 ; 45.2]$ & $29.7[21.0 ; 44.6]$ & $0.99(0.79 ; 1.01)$ & n.s. \\
\hline Total relax. time (\%, median [IQR]) & $6.7[4.0 ; 11.5]$ & $6.9[4.6 ; 12.5]$ & $0.99(0.67 ; 1.47)$ & n.s. \\
\hline Upright relax. time (\%, median [IQR]) & $7.2[4.1 ; 13.2]$ & $8.3[4.7 ; 14.0]$ & $0.99(0.96 ; 1.03)$ & n.s. \\
\hline Lying relax. time (\%, median [IQR]) & $3.1[0.0 ; 12.8]$ & $3.4[0.6 ; 8.6]$ & $1.01(0.97 ; 1.04)$ & n.s. \\
\hline \multicolumn{5}{|l|}{ Barium esophagogram } \\
\hline Hiatal hernia (n [\%]) & 32 [49.2] & $92[70.8]$ & $0.52(0.28 ; 0.96)$ & 0.035 \\
\hline Reflux (n [\%]) & $28[43.1]$ & $68[52.3]$ & $0.81(0.44 ; 1.42)$ & n.s. \\
\hline
\end{tabular}

n.s. not significant; ${ }^{\#} n=58$ (seven patients did not tolerate manometry), ${ }^{+} n=129$ (one patient did not tolerate manometry), $p p$-value; all parameters were tested using univariate logistic regression models.

\section{Discussion}

Diabetes is a major health problem, as it is an important contributor to various other diseases and its incidence still continues to rise. Despite the fact that its role as a risk factor for GERD has been demonstrated and that GERD itself is of high clinical relevance, little light has been shed on the connection between the two diseases $[3,4,6]$. For the first time, the present study characterizes GERD patients concurrently affected by T2D using well-established diagnostic methods for oesophageal testing.

The individual symptom load differs between diabetics and non-diabetics [19]. In our study, dysphagia and globus sensation were found significantly more frequently in GERD patients with T2D. In the course of GERD, dysphagia may be caused by decreased oesophageal motility or by peptic oesophageal stricture due to acid reflux [20,21]. In our study population, impaired peristalsis, as assessed by manometry, was somewhat more frequent among patients with T2D. Moreover, dysphagia has been shown to be related to the presence of high LES pressure in patients with a hypertensive LES [22,23], which is also true for our investigation.

Globus sensation has been reported to be a common functional symptom due to inflammation of the throat caused by GERD $[24,25]$. In our study, however, there was no significant difference in DeMeester scores between the two groups. Diabetics used antidepressants more frequently than non-diabetics. Psychological impairment has been discussed as another possible factor contributing to globus sensation [26]. The approximately two-fold higher prevalence of laryngeal lesions in patients with T2D may also contribute to the increased prevalence of globus sensation. The exact etiology of globus sensation, however, remains incompletely understood $[27,28]$.

Epigastric pain and heartburn are known to be the most frequent GERD-associated symptoms, occurring in up to $90 \%$ of patients with proven T2D [29]. Similar results have been found in the present investigation. The higher prevalence of heartburn, defined as "hypersensitivity" to acid reflux in the non-diabetes group, may be explained, at least partly, by diabetic neuropathy $[4,8,30]$. Moreover, the higher rates of hiatal hernia in the non-diabetes group in our study may have also contributed to the higher heartburn rate [31]. However, epigastric pain and heartburn are not necessarily associated with GERD. Studies that deal with symptoms only, without oesophageal testing, cannot verify the actual presence of GERD [3-5,9,10]. Thus, a 
direct comparison between the results of these studies and our findings is not valid.

Regurgitation, a major problem for many reflux patients, is predominant in non-diabetics and within the range described for this population [8]. Increased rates of hiatal hernia in the non-diabetes group may have had an impact on this finding [31]. For patients with T2D, however, the regurgitation rate of about $48 \%$ was much higher in our study compared to $16 \%$ in a previous series of type 2 diabetics [32]. Impaired peristalsis was found more frequently in patients with T2D, which may be another explaination for our findings.

Microaspiration of the gastro-oesophageal refluate and subsequent airway inflammation, are the major mechanisms that cause respiratory symptoms in GERD patients [33-35]. Although the overall prevalence of respiratory symptoms did not differ between T2D patients and nondiabetics, it is noteworthy that laryngeal lesions, including leukoplakia and ulcerations, were observed more frequently in patients with T2D. Recently, epidemiologic evidence has suggested that cancer incidence is associated with DM, as well as certain diabetic risk factors, including obesity [36-38]. Our goal, however, was not the long-term observation of possible precancerous lesions. Nevertheless, to the best of our knowledge, this is the first report describing extra-oesophageal reflux symptoms in diabetic GERD patients.

Overall, the summed scores of GERD symptoms were comparable in diabetics and non-diabetics in our study. Similar results have been published earlier [19,39]. Likewise, GERD-specific quality of life was comparable in diabetic and non-diabetic patients although there were some minor differences in health related quality of life [40]. All in all, data on the prevalence of reflux symptoms vary widely within T2D patients, ranging from $25.3 \%$ to $45.0 \%$ $[3,39]$. In contrast to other studies, we did not screen for GERD-related symptoms in diabetics since these symptoms were an inclusion criterion in our study.

Notably, the duration of $\mathrm{T} 2 \mathrm{D}$ and the presence of neuropathia had no major impact on GERD symptoms in our investigation [41,42]. In the present series, this was not the case. This is probably due to the fact that (i) patients with T2D were under adequate glycaemic control, has already been pointed out earlier $[3,9,43]$. Moreover, (ii) the duration of GERD symptoms did not differ compared to non-diabetics.

Hiatal hernia rates were relatively high in both groups. Patients referred to our motility laboratories for GERD diagnostics are usually those who still suffer from GERDrelated symptoms despite PPI intake. In general, hiatal hernia is the major reason for persisting complaints [44]. This could possibly be some kind of 'pre-selection' of our patients. However hiatal hernia rates were more frequent in non-diabetics. This is a surprising result considering that higher BMI levels are known to be a risk factor for the presence of hiatal hernia, and that higher BMI levels were found in patients with T2D in our study $[37,45]$. Nevertheless, our results are in accordance with a previous report demonstrating that, in morbidly obese patients, the rate of hiatal hernia was inversely correlated with glycaemic control [46]. In diabetics, delayed gastric emptying and decreased proximal retention of meals have been reported [47]. Furthermore, an inverse correlation between proximal gastric volume and the formation of a sliding hiatal hernia has been described [48]. Thus, altered intragastric meal distribution in patients with T2D may contribute to a lower prevalence of hiatal hernias in diabetic patients.

Higher BMI levels, as found in the T2D patients in our study, are an established risk factor for the development of GERD, and, thus, for esophagitis [49]. Notably, histological rates of esophagitis and Barrett's oesophagus, as well as low-grade and high-grade dysplasia, were somewhat higher in T2D patients compared to controls. Although these results failed to reach statistical significance, which is probably due to the relatively low number of patients, one has to emphasize the possible clinical importance of such results, because, for example, low-grade dysplasia was more than twice as high in diabetics than in non-diabetics $(10.8 \%$ vs. $3.8 \%)$. It has already been suggested that visceral fat, another contributing factor to T2D, was associated with Barrett's esophagitis, and with increased esophageal inflammation and high-grade dysplasia in subjects with Barrett's esophagitis [50]. Moreover, since patients with T2D may have a lower oesophageal sensitivity, as suggested by the decreased heartburn rates, GERD and, in consequence, precancerous lesions, might be diagnosed later than in non-diabetics. However, the primary goal of our study was not to prove the increased risk of T2D patients for developing oesophageal adenocarcinoma, but to describe T2D-related differences in the symptom load and the pathophysiology of GERD. Consequently, surveillance studies will be necessary in order to explore the cancerous potential of T2D in GERD patients.

Our results showed significantly higher rates of helicobacter pylori infection in patients with T2D. This is in accordance with the published literature, as diabetics, especially those with poor glycaemic control, are more prone to infections $[8,43]$. Nevertheless, other studies reported even higher percentages of helicobacter pylori infection, with differences between diabetics and nondiabetics of up to $80 \%$ versus $30 \%$, respectively [51,52]. The discrepancy between these results and our findings may be explained by the fact that many of our patients had been pretreated by eradication therapy.

Hyperglycaemia decreases LES pressure in diabetics, with up to $92 \%$ of patients having resting LES pressure 
between 0 and $8 \mathrm{mmHG}$ [30]. Consequently, lower LES pressure predisposes to GERD [8]. In our investigation, however, T2D patients had significantly higher LES pressure levels compared to non-diabetics. Various studies have dealt with LES pressure in diabetic subjects $[30,53]$. However, these data are only partly comparable to our results, since all of these studies included diabetic patients without a history of GERD.

DeMeester scores were lower in T2D patients, although not statistically significant. The higher prevalence of hiatal hernia in the non-diabetic group and the significantly lower LES pressure may account for this finding. In addition, high helicobacter pylori infection rates could have ameliorated gastric secretion [8].

Notably, our data show no significant correlations between HbA1c levels and LES pressure, relaxation time, or peristalsis. Gastrointestinal symptoms and complications do not always correlate with the duration of DM and glycaemic control [43]. To date, no single risk factor for GERD in T2D has been identified, as the aetiology of GERD is multifactorial [43].

The limitation of our study is the retrosprective design, although all data were derived from a prospective database. The relatively low number of patients might be considered another drawback of the study. To the best of our knowledge, however, this is the largest investigation on proven GERD in T2D.

\section{Conclusion}

T2D GERD patients (i) exhibit other types of symptoms than do non-diabetics, especially dysphagia, globus sensation, and, at least to some extent, extra-oesophageal symptoms with higher rates of proven laryngeal lesions; (ii) are infected with helicobacter pylori more frequently; and (iii) show higher LES pressure levels; and (iv) lower rates of hiatal hernia. The results may have some implications for diagnostic and therapeutic strategies in diabetic GERD patients. Since the incidence of the most frequently encountered GERD symptom, namely heartburn, is lower in patients with T2D, other signs and symptoms should lead to the suspected diagnosis of GERD. Particularly with regard to possibly higher rates of dysplasia and Barrett metaplasia in T2D GERD patients, the diagnostic work-up in diabetic patients could be of the utmost importance.

\section{Abbreviations}

GERD: Gastro-oesophageal reflux disease; T2D: Diabetes mellitus type 2;

LES: Lower oesophageal sphincter; BMI: Body mass index; DM: Diabetes mellitus.

\section{Competing interest}

All authors agree to the manuscript's submission, confirm that our manuscript is not submitted or being considered for publication elsewhere in any until your editorial decision, and agree that if accepted the paper will not subsequently be published in the same or similar form in any language without the written consent of the publisher. All authors have read and approved the final version of the manuscript.
All authors declare that they have no commercial interest, financial interest, and/or another relationship with manufacturers of pharmaceuticals,

laboratory supplies, and/or medical devices or with commercial providers of medically related services. There was no funding.

\section{Authors' contributions}

RP contributed to the project's conception, participated in acquisition of data and drafted the manuscript. OR and GS performed the statistical analysis. MG and JO performed the statistical analysis and drafted the manuscript. JL and FMR contributed to the project's conception. WHE participated in acquisition of data. MG contributed to the project's conception. CN contributed to the project's conception, data and drafted the manuscript. All authors read and approved the final manuscript.

\section{Acknowledgment}

We are indebted to Dr. Barbara Izay for statistical support.

\section{Dedication}

This study is dedicated to Prof Dr Michael Gadenstätter (1963-2013), who recently passed away unexpectedly. We will keep him in memory as a friendly end engaged chief of the Department of Surgery, General Hospital of Krems, Austria. Professor Gadenstätter substantially contributed to GERD literature and antireflux surgery. We keep him in kind remembrance.

\section{Author details}

${ }^{1}$ Division of General Surgery, Department of Surgery, Medical University of Vienna, Vienna, Austria. ${ }^{2}$ Karl Landsteiner Institute for Clinical Surgery, General Hospital of Krems, Krems, Austria. ${ }^{3}$ Division of Plastic and Reconstructive Surgery, Department of Surgery, Medical University of Vienna, Vienna, Austria. ${ }^{4}$ Department of Gynecology and Obstetrics, Medical University of Vienna, Vienna, Austria. ${ }^{5}$ Division of Vascular Surgery, Department of Surgery, Medical University of Vienna, Vienna, Austria.

Received: 21 March 2013 Accepted: 14 August 2013 Published: 23 August 2013

\section{References}

1. Moayyedi P, Talley NJ: Gastro-oesophageal reflux disease. Lancet 2006, 367:2086-2100.

2. Shaw JE, Sicree RA, Zimmet PZ: Global estimates of the prevalence of diabetes for 2010 and 2030. Diabetes Res Clin Pract 2010, 87:4-14.

3. Nishida T, Tsuji S, Tsujii M, Arimitsu S, Sato T, Haruna Y, Miyamoto T, Kanda T, Kawano S, Hori M: Gastroesophageal reflux disease related to diabetes: analysis of 241 cases with type 2 diabetes mellitus. J Gastroenterol Hepatol 2004, 19:258-265.

4. Wang X, Pitchumoni CS, Chandrarana K, Shah N: Increased prevalence of symptoms of gastrooesophageal reflux diseases in type 2 diabetics with neuropathy. World J Gastroenterol 2008, 14:709-712.

5. Ariizumi K, Koike T, Ohara S, Inomata Y, Abe Y, lijima K, Imatani A, Oka T, Shimosegawa $\mathrm{T}$ : Incidence of reflux esophagitis and $\mathrm{H}$ pylori infection in diabetic patients. World J Gastroenterol 2008, 14:3212-3217.

6. Horikawa A, Ishii-Nozawa R, Ohguro M, Takagi S, Ohtuji M, Yamada M, Kuzuya N, Ujihara N, Ujihara M, Takeuchi K: Prevalence of GORD (gastroooesophageal reflux disease) in type 2 diabetes and a comparison of clinical profiles between diabetic patients with and without GORD. Diabet Med 2009, 26:228-233.

7. Niigaki M, Adachi K, Hirakawa K, Furuta K, Kinoshita Y: Association between metabolic syndrome and prevalence of gastrooesophageal reflux disease in a health screening facility in Japan. J Gastroentero/ 2012. Sep 14. [Epub ahead of print].

8. Promberger R, Gadenstätter M, Ciovica R, Schwab G, Neumayer C: Gastrooesophageal reflux disease in diabetic patients: a systematic review. Eur Surg 2007, 39:340-354.

9. Kase H, Hattori Y, Sato N, Banba N, Kasai K: Symptoms of gastrooesophageal reflux in diabetes patients. Diabetes Res Clin Pract 2008, 79:6-7.

10. Holub JL, Silberg DG, Michaels LC, Williams JL, Morris CD, Eisen G: Acidrelated upper endoscopy findings in patients with diabetes versus nondiabetic patients. Dig Dis Sci 2010, 55:2853-2859.

11. Hall JC, Hall JL: Emergence of 'retropro' studies in the surgical literature. ANZ J Surg 2008, 78:411-413. 
12. American Diabetes Association: Standards of medical care in diabetes2006. Diabetes Care 2006, 29:S4-S42.

13. Ollyo JB, Fontolliet C, Lang BF: La nouvelle classification de savary des oesophagites de reflux. Acta Endosc 1992, 22:307-320.

14. Riddell $\mathrm{RH}$ : The biopsy diagnosis of gastrooesophageal reflux disease, "carditis," and Barrett's esophagus, and sequelae of therapy. Am J Surg Pathol 1996, 20:S31-S50.

15. Zaninotto G, DeMeester TR, Schwizer W, Johansson KE, Cheng SC: The lower oesophageal sphincter in health and disease. Am J Surg 1988, 155:104-111.

16. Kaul BK, DeMeester TR, Oka M, Ball CS, Stein HJ, Kim CB, Cheng SC: The cause of dysphagia in uncomplicated sliding hiatal hernia and its relief by hiatal herniorrhaphy. A roentgenographic, manometric, and clinical study. Ann Surg 1990, 211:406-410.

17. Richter JE, Wu WC, Johns DN, Blackwell JN, Nelson JL 3rd, Castell JA, Castel DO: Oesophageal manometry in 95 healthy adult volunteers. Variability of pressures with age and frequency of "abnormal" contractions. Dig Dis Sci 1987, 32:583-592.

18. DeMeester TR, Wang Cl, Wernly JA, Pellegrini CA, Little AG, Klementschitsch $P$, Bermudez G, Johnson LF, Skinner DB: Technique, indications, and clinical use of 24 hour oesophageal pH monitoring. J Thorac Cardiovasc Surg 1980, 79:656-670.

19. Hsu CS, Wang PC, Chen JH, Su WC, Tseng TC, Chen HD, Hsiao TH, Wang CC, Lin HH, Shyu RY, Chao YC: Increasing insulin resistance is associated with increased severity and prevalence of gastro-oesophageal reflux disease. Aliment Pharmacol Ther 2011, 34:994-1004.

20. Ahuja $V$, Yencha MW, Lassen LF: Head and neck manifestations of gastrooesophageal reflux disease. Am Fam Physician 1999, 60:873-886.

21. Said A, Brust DJ, Gaumnitz EA, Reichelderfer M: Predictors of early recurrence of benign oesophageal strictures. Am J Gastroenterol 2003, 98:1252-1256

22. GadEl-Hak NA, Mostafa M, AbdelHamid Hussein Haleem M: Hypertensive lower oesophageal sphincter (HLES): prevalence, symptoms genesis and effect of pneumatic balloon dilatation. Saudi Gastroenterol 2006, 12:77-82.

23. Bonatti $H$, Achem SR, Hinder RA: Impact of changing epidemiology of gastrooesophageal reflux disease on its diagnosis and treatment. J Gastrointest Surg 2008, 12:373-381.

24. Rosanowski F, Eysholdt U: ENT manifestations of gastrooesophageal reflux. Internist (Berl) 2003, 44:63-67.

25. Hill J, Stuart RC, Fung HK, Ng EK, Cheung FM, Chung CS, van Hasselt CA: Gastrooesophageal reflux, motility disorders, and psychological profiles in the etiology of globus pharyngis. Laryngoscope 1997, 107:1373.

26. Martín-Merino E, Ruigómez A, García Rodríguez LA, Wallander MA, Johansson S: Depression and treatment with antidepressants are associated with the development of gastro-ooesophageal reflux disease. Aliment Pharmacol Ther 2010, 31:1132-1140.

27. Rakshit R, de Caestecker J: Globus: are we any nearer to understanding it? Am J Gastroenterol 2009, 104:299-301.

28. Kwiatek MA, Mirza F, Kahrilas PJ, Pandolfino JE: Hyperdynamic upper oesophageal sphincter pressure: a manometric observation in patients reporting globus sensation. Am J Gastroenterol 2009, 104:289-298.

29. Wang KK, Sampliner RE: Practice parameters committee of the American college of gastroenterology. Updated guidelines 2008 for the diagnosis, surveillance and therapy of Barrett's esophagus. Am J Gastroentero/ 2008, 103:788-797.

30. Hüppe D, Tegenthoff M, Faig J, Brunke F, Depka S, Stuhldreier M, Micklefield $G$, Gillissen A, May B: Oesophageal dysfunction in diabetes mellitus: is there a relation to clinical manifestation of neuropathy? Clin Investig 1992, 70:740-747.

31. Petersen H, Johannessen T, Sandvik AK, Kleveland PM, Brenna E, Waldum H, Dybdahl JD: Relationship between endoscopic hiatus hernia and gastroesophageal reflux symptoms. Scand J Gastroenterol 1991, 26:921-926.

32. Xia HH, Talley NJ, Kam EP, Young LJ, Hammer J, Horowitz M: Helicobacter pylori infection is not associated with diabetes mellitus, nor with upper gastrointestinal symptoms in diabetes mellitus. Am J Gastroenterol 2001, 96:1039-1046

33. Labenz J: Facts and fantasies in extra-ooesophageal symptoms in GORD Best Pract Res Clin Gastroenterol 2010, 24:893-904.

34. Chang AB, Lasserson TJ, Gaffney J, Connor FL, Garske LA: Gastroooesophageal reflux treatment for prolonged non-specific cough in children and adults. Cochrane Database Syst Rev 2011, 1, CD004823.
35. Ciovica R, Gadenstätter M, Klingler A, Neumayer C, Schwab GP: Laparoscopic antireflux surgery provides excellent results and quality of life in gastrooesophageal reflux disease patients with respiratory symptoms. J Gastrointest Surg 2005, 9:633-637.

36. Giovannucci E, Harlan DM, Archer MC, Bergenstal RM, Gapstur SM, Habel LA, Pollak M, Regensteiner JG, Yee D: Diabetes and cancer: a consensus report. Diabetes Care 2010, 33:1674-1685.

37. Li Q, Zhang J, Zhou Y, Qiao L: Obesity and gastric cancer. Front Biosci 2012, 17:2383-2390

38. Tian T, Zhang LQ, Ma XH, Zhou JN, Shen J: Diabetes mellitus and incidence and mortality of gastric cancer: a meta-analysis. Exp Clin Endocrinol Diabetes 2012, 120:217-223.

39. Nozu T, Komiyama H: Clinical characteristics of asymptomatic esophagitis. J Gastroenterol 2008, 43:27-31.

40. Promberger R, Spitzer A, Ott J, Lenglinger J, Eilenberg W, Gadenstätter M, Neumayer C: Quality of life in type 2 diabetics with gastroesophageal reflux disease: a case control study. Eur Surg 2013, 45:194-199.

41. Clouse RE, Lustman PF: Gastrointestinal symptoms in diabetic patients: lack of associationwith neuropathy. Am J Gastroenterol 1989, 84:868-872.

42. Lee SD, Keum B, Chun HJ, Bak YT: Gastrooesophageal reflux disease in type II diabetes mellitus with or without peripheral neuropathy. J Neurogastroenterol Motil 2011, 17:274-278.

43. Sellin $J H$, Chang EB: Therapy insight: gastrointestinal complications of diabetes-pathophysiology and management. Nat Clin Pract Gastroenterol Hepatol 2008, 5:162-171.

44. Neumayer C, Ciovica R, Gadenstätter M, Erd G, Leidl S, Lehr S, Schwab G: Significant weight loss after laparoscopic Nissen fundoplication. Surg Endosc 2005, 19:15-20.

45. Friedenberg FK, Xanthopoulos M, Foster GD, Richter JE: The association between gastrooesophageal reflux disease and obesity. Am $J$ Gastroenterol 2008, 103:2111-2122.

46. Lauffer A, Forcelini CM, Ruas LO, Madalosso CA, Fornari F: Gastrooesophageal reflux disease is inversely related with glycemic control in morbidly obese patients. Obes Surg 2011, 21:864-870.

47. Stacher $\mathrm{G}$, Lenglinger J, Bergmann $\mathrm{H}$, Schneider C, Brannath W, Festa A, Meghdadi S, Stacher-Janotta G: Impaired gastric emptying and altered intragastric meal distribution in diabetes mellitus related to autonomic neuropathy? Dig Dis Sci 2003, 48:1027-1034

48. Scheffer RC, Bredenoord AJ, Hebbard GS, Smout AJ, Samsom M: Effect of proximal gastric volume on hiatal hernia. Neurogastroenterol Motil 2010, 22:552-556.

49. Choi CW, Kim GH, Song CS, Wang SG, Lee BJ IH, Kang DH, Song GA: Is obesity associated with gastropharyngeal reflux disease? World J Gastroenterol 2008, 14:265-271.

50. Nelsen EM, Kirihara Y, Takahashi N, Shi Q, Lewis JT, Namasivayam V, Buttar NS, Dunagan KT, Prasad GA: Distribution of body fat and its influence on esophageal inflammation and dysplasia in patients with Barrett's esophagus. Clin Gastroenterol Hepatol 2012, 10:728-734.

51. Ko GT, Chan FK, Chan WB, Sung JJ, Tsoi CL, To KF, Lai CW, Cockram CS: Helicobacter pylori infection in Chinese subjects with type 2 diabetes. Endocr Res 2001, 27:171-177.

52. Quadri R, Rossi C, Catalfamo E, Masoero G, Lombardo L, Della Monica P, Rovera L, Pera A, Cavello Perin P: Helicobacter pylori infection in type 2 diabetic patients. Nutr Metab Cardiovasc Dis 2000, 10:263-266.

53. Lluch I, Ascaso JF, Mora F, Minguez M, Peña A, Hernandez A, Benages A: Gastrooesophageal reflux in diabetes mellitus. Am J Gastroenterol 1999, 94:919-924.

doi:10.1186/1471-230X-13-132

Cite this article as: Promberger et al:: Gastro-oesophageal reflux disease in type 2 diabetics: symptom load and pathophysiologic aspects - a retro-pro study. BMC Gastroenterology 2013 13:132. 